Pak. j. sci. ind. res. Ser. A: phys. sci. 201558 (1) 1-7

\title{
Catalytic Hydrodechlorination of 2,4-Dichlorophenol Using Co-Current Down Flow Contactor Reactor
}

\author{
Asim Rehman ${ }^{a *}$, Muhammad Nawaz ${ }^{\mathrm{b}}$, Arshad Chughtai ${ }^{\mathrm{c}}$, Muhammad Arif Butt ${ }^{\mathrm{a}}$ and \\ Abdul Sattar \\ ${ }^{a}$ Institute of Chemical Engineering and Technology, University of The Punjab, Quaid-e-Azam Campus, \\ Lahore 54590, Pakistan \\ ${ }^{\mathrm{b}}$ School of Chemical Engineering, The University of Faisalabad, Faisalabad, Pakistan \\ ${ }^{\mathrm{c}}$ School of Chemical and Materials Engineering, National University of Sciences and Technology, \\ H-12 Islamabad, Pakistan
}

(received July 1, 2013; revised February 16, 2014; accepted February 18, 2014)

\begin{abstract}
In this study, a new prospective regarding application of gas liquid reactions in the presence of catalyst was studied for pollution abatement in the novel reactor. Catalytic hydrodechlorination (CHDC) of 2,4-dichlorophenol (2,4-DCP) in aqueous system was carried out under the operating conditions at 25 $75^{\circ} \mathrm{C}, 1 \mathrm{~atm}$ in co-current down flow contactor reactor. Under these reaction conditions complete conversion of 2,4-DCP into less toxic products (phenol and cyclohexanone) was achieved using $5 \% \mathrm{Pd} / \mathrm{C}$ catalyst. At typical temperature the hydrodechlorination reaction of 2,4-DCP was completed after 10 min. 2,4-DCP was converted to $96.19 \%$ of phenol and $3.81 \%$ of cyclohexanone using $0.4 \mathrm{~g} / \mathrm{L}$ of $5 \% \mathrm{Pd} / \mathrm{C}$ catalyst. The increase in initial concentration of 2,4-DCP resulted in the increase in time for the dechlorination of 2,4DCP. The calculated activation energy values amounted to $43 \mathrm{KJ} / \mathrm{mol}$ for the CHDC of 2,4-DCP exhibiting that this reaction occurs mainly under the surface reaction rate controlled condition.
\end{abstract}

Keywords: catalytic hydrodechlorination, 2,4-dichlorophenol, palladium, carbon, co-current downflow contactor reactor

\section{Introduction}

Chlorophenols (CPs) are extensively used in the production of herbicides, dyes, wood protectors and plant regulators. The wastewater coming from such industries has a considerable and variable amount of CPs which is highly toxic and poorly biodegradable as reported by Czaplicka (2004). Due to their high toxicity and resistance to degradation, CPs have been listed as priority pollutants as per Proposition 65 by the Environmental Protection Agency, USA (EPA, 2005) and as per WHO guidelines (WHO, 1996) on CPs in drinking water.

CPs are widely distributed in the environment in different forms such as dissociated, non-dissociated and adsorbed on the suspended matters. Reported studies of Sithole et al. (1986) and Czaplicka (2001), state that CPs are present in reservoirs, surface water and in sediments. In ambient air, CPs are present as a result of vapours coming from the production related activities utilising chlorine, combustion of wastes, coal and wood. As per Berg (1990), the effect on ambient air is directly related to the local

\footnotetext{
*Author for correspondence; E-mail: asim_rehman@live.com
}

emission source. In soil, the presence of CPs is the result of wastewater discharge from the chlorinated industries, biodegradation of herbicides and pesticides. The transportation of contaminants in soil was studied by Knuutinen et al. (1990) which is affected by the $\mathrm{pH}$ of the soil, nature of contaminant, solubility in water, evaporation rates and biodegradation rates.

The catalytic hydrodechlorination (CHDC) has different advantages over the oxidation process such as the selectivity of different types of the catalysts, chemical reactors and mild reaction conditions. It offers a possible unit process having cost effectiveness in which chlorine is converted to salt (chloride ion) and phenol into saturated cyclic alcohol i.e., cyclohexanol (Vaidya and Mahajani, 2004). CHDC has a wide range of application in chlorobenzene (Meshesha et al., 2009), both in gas phase (Keane and Murzin, 2001) and multiphase mixture (Murena and Giogia, 2004), chloroethylenes (Concibido et al., 2005; Nishijima et al., 2004), chlorobiphenyls (Gryglewicz et al., 2006), carbon tetrachloride (GomezSainero et al., 2002; 2000) and chloroethanes (Mori et al., 2004). The precious metal Pd, Pt, and Rh exhibited 
the highest activity in the $\mathrm{CHDC}$ reaction with a wide range of supported metals such as $\mathrm{Pd} / \mathrm{C}, \mathrm{Pd} / \mathrm{Al}_{2} \mathrm{O}_{3}$ and $\mathrm{Rh} / \mathrm{C}$ (Yuan and Keane, 2003), $\mathrm{Ru}-\mathrm{Pd} / \mathrm{TiO}_{2}$ (Vaidya and Mahajani, 2004), $\mathrm{Pd} / \mathrm{Mg}(\mathrm{Al}) \mathrm{O}$ (Meshesha et al., 2009), $\mathrm{Pd}, \mathrm{Pt}, \mathrm{Rh} / \mathrm{Al}_{2} \mathrm{O}_{3}$ (Diaz et al., 2008), $\mathrm{Pd} / \mathrm{SiO}_{2}$ (Jujjuri et al., 2009), $\mathrm{Pd} / \mathrm{Fe}$ (Graham et al., 2005) and $\mathrm{Pd} /$ activated carbon (Xia et al., 2009; Da-Silva et al., 2007; Calvo et al., 2004).

The co-current downflow contactor reactor (CDCR) was initially used for the hydrogenation of Iatonic acid by Lu et al. (1996) and 2-butyne 1,4-diol by Winterbottom et al. (2003). The reactor exhibited excellent gas liquid mass transfer characteristics as a slurry reactor with the following characteristics i.e., high gas holdup, high mass transfer efficiencies, improved selectivity and process intensive. During the evaluation of mass transfer characteristics of CDCR in a fermentation broth (Dursun et al., 1999), the result indicates that $K_{L a}$ and gas holdup increases with increasing liquid and gas flow rate and is suitable for biotechnological processes. Due to significant advantages over conventional bubble column reactor, the CDCR was used in the photocatalytic oxidation reactions of chlorophenols by Ochuma and Fishwick (2007a) and Ochuma and Osibo (2007b). The results indicate that inherit characteristics of CDCR resulted in complete demineralisation in the short reaction time.

The objective of this study was to carry out CHDC reaction of 2,4-DCP in CDCR in the presence of $\mathrm{Pd} / \mathrm{C}$ catalyst under mild reaction conditions. It is the first time that CDCR was used for CHDC reaction studies.

\section{Materials and Methods}

Materials. $\mathrm{Pd} / \mathrm{C}$ catalyst 5\% was purchased from GFS chemicals and used without further treatment. In all the experiments 2,4-DCP (purity $>99 \%$ ) of Alfa Aesar, 2-CP (purity $>98 \%$ ) of Fluka and following chemicals of Merck 4-CP (purity $>98 \%$ ), cyclohexanol (purity $>98 \%$ ), cyclohexanone (purity $>98 \%$ ), phenol (purity $>99 \%$ ) and sodium hydroxide (purity 99-100\%) were used. For preparation of solutions during the experimentation, deionised water was used and hydrogen and nitrogen gases having $99.99 \%$ purity were used in experimentations.

Hydrodechlorination reactor (CDCR). All experiments were carried out in the CDCR and schematic diagram of reactor is represented in Fig. 1. In the CDCR hydrogen gas and reaction mixture $(2,4-\mathrm{DCP}, 5 \% \mathrm{Pd} / \mathrm{C}$

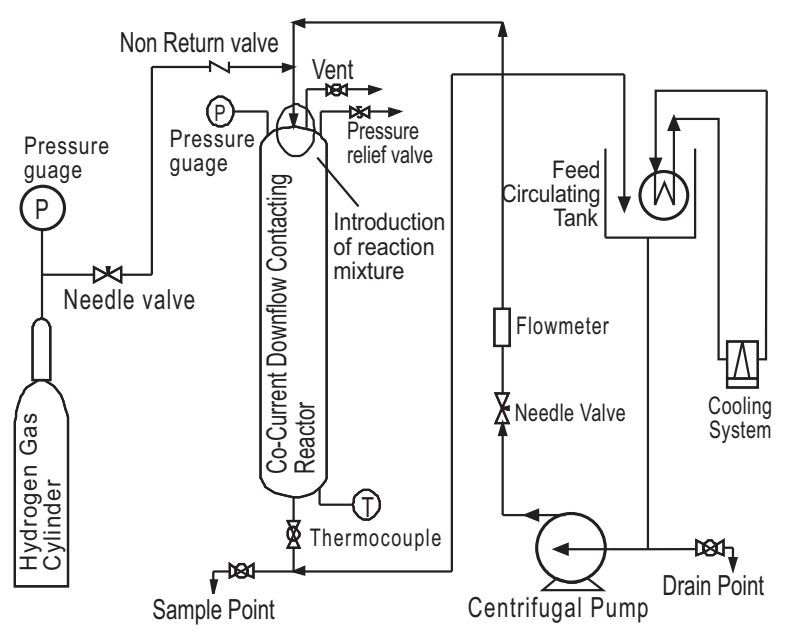

Fig. 1. Schematic diagram for CHDC reaction in CDCR.

catalyst $\& \mathrm{NaOH}$ ) were introduced at the top of a fully flooded column co-currently through an orifice having diameter $0.5 \mathrm{~mm}$. As a result, in the upper section of the fully flooded column, vigorous gas-liquid dispersion was formed by the high velocity liquid jet which prevents the formation of gas pockets at the top section. During the whole reaction, the gas bubble rise velocity was at higher side with reference to the down flow liquid velocity in the CDCR which prevents, at the bottom, the entrainment of gas bubbles. Due to this, nearly uniform sized bubble dispersion was formed throughout the column. At the bottom of the CDCR and throughout the dispersion, the coalescence occurd producing larger bubbles to rise up which were smashed up by the incoming high velocity inlet liquid stream having the fresh inlet gas which then impulsively merged in the inlet region to give the distinctive and uniform bubble size. The total volume of the system was $6 \mathrm{~L}$ with QVF glass column having dia $0.0381 \mathrm{~m}$ and length $2.43 \mathrm{~m}$. The flow rate of liquid was $1.8 \mathrm{~L} / \mathrm{min}$, whereas the flow of $\mathrm{H}_{2}$ gas was kept constant in all the experiments.

Product analysis. The concentration of 2,4-DCP and reaction products was determined by gas chromatograph having model VARIAN CP 3800 in flame ionisation detector mode and VF-5ms column ( $30 \mathrm{~m}$ in length, $0.25 \mu \mathrm{m}$ film thickness and $\varnothing 0.25 \mathrm{~mm}$ ). The temperature of column was programmed from $60^{\circ} \mathrm{C}$ to $110^{\circ} \mathrm{C}$ ( 2 min held) at the rate of $5^{\circ} \mathrm{C} / \mathrm{min}$ and then to $220^{\circ} \mathrm{C}(3 \mathrm{~min}$ held $)$ at a rate of $10^{\circ} \mathrm{C} / \mathrm{min}$. Nitrogen gas was used as a carrier gas having flow rate of $1.4 \mathrm{~mL} / \mathrm{min}$ under pressure of $8.5 \mathrm{psi}$. The injector and detector temperature was set at $250^{\circ} \mathrm{C}$. The identification of components of product mixture was carried 
out by comparing the retention times of the solutes with standard chemicals and also with the help of co-injection technique.

\section{Results and Discussion}

In order to establish optimum conditions for CHDC of 2,4-DCP, the effect of pressure, temperature of the reaction media, the effect of catalyst loading and initial concentration of 2,4-DCP was investigated.

Effect of pressure. The effect of pressure was investigated by applying different pressures in CDCR. The effect of pressure was studied by using $489 \mathrm{mg} / \mathrm{L}$ of 2,4-DCP, $0.3 \mathrm{~g} / \mathrm{L}$ of $5 \% \mathrm{Pd} / \mathrm{C}$ at $25{ }^{\circ} \mathrm{C}$ with the dispersion height of $40 \mathrm{~cm}$. At 1 bar pressure the hydrodechlorination of 2,4-DCP was achieved in $45 \mathrm{~min}$ with the $0.52 \%$ of cyclohexanone and $99.48 \%$ of phenol. With the increase of
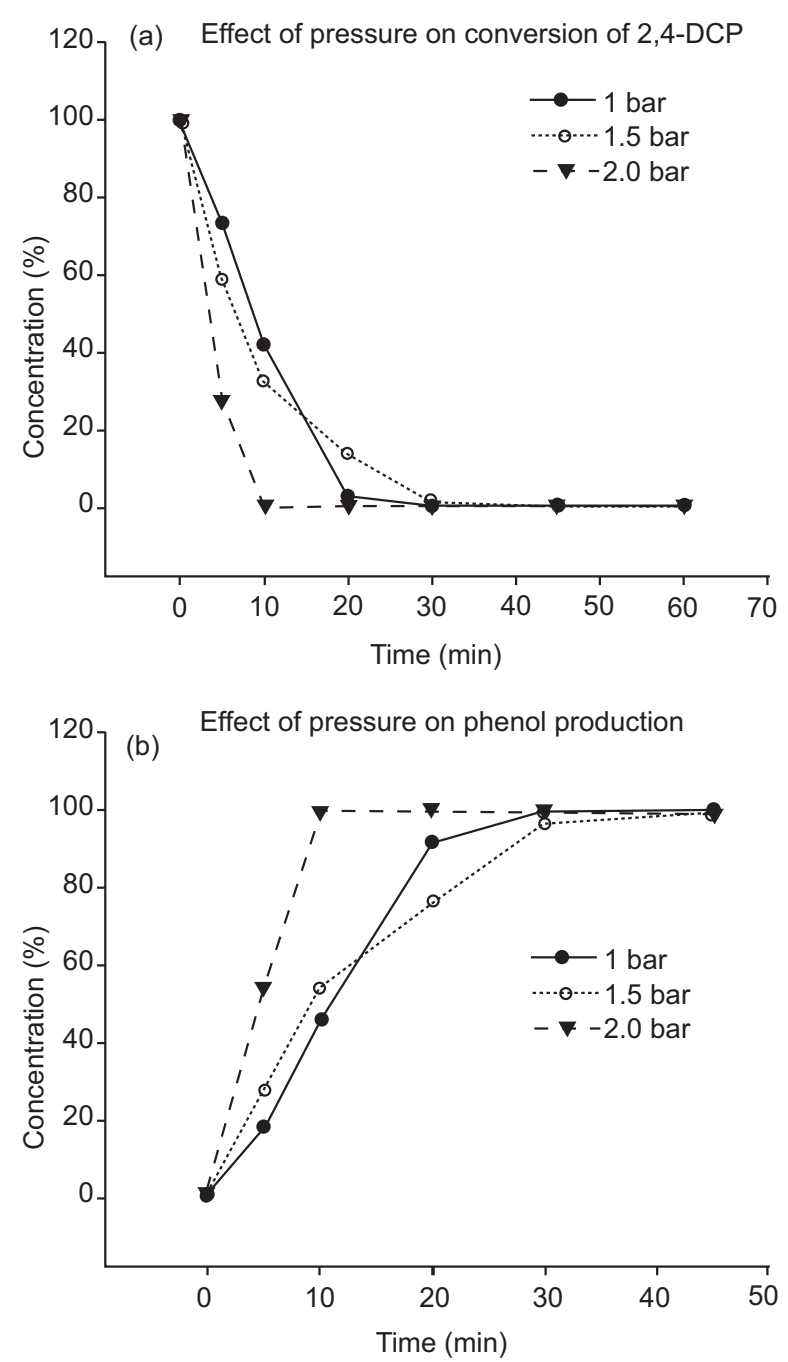

Fig. 2(a-b). The effect of pressure on the CHDC of 2,4-DCP. pressure (at 2 bar) the conversion was very rapid as shown in Fig. 2(a-b) that, after $10 \mathrm{~min}, 2,4-\mathrm{DCP}$ was totally hydrodechlorinated with the $4.46 \%$ of cyclohexanone and $95.54 \%$ of phenol. Identical results were reported by Calvo et al. (2004) conforming that the CHDC reaction can be carried out under mild pressure (2.4-3 bar) in fixed bed reactor however for CDCR the optimum pressure range is 1-2 bar. The increase in pressure resulted in high activity of the reaction and the reaction completed in the shortest time $(\sim 10 \mathrm{~min})$ as the solubility increases the rate of reaction increases.

Effect of temperature. The reaction was carried out at $25^{\circ} \mathrm{C}, 35^{\circ} \mathrm{C}$ and $45^{\circ} \mathrm{C}$ by using initial concentration of 2,4-DCP as $489 \mathrm{mg} / \mathrm{L}, 0.3 \mathrm{~g} / \mathrm{L}$ of $5 \% \mathrm{Pd} / \mathrm{C}$, dispersion height $40 \mathrm{~cm}$ and at 1 bar of pressure. At $25^{\circ} \mathrm{C}$ the reaction was completed within $30 \mathrm{~min}$ whereas the complete conversion of 2,4-DCP was achieved within $20 \mathrm{~min}$ at $45^{\circ} \mathrm{C}$ and $2.47 \%$ of cyclohexanone was produced as the end product. The 2-CP and 4-CP were formed as the intermediate products but after $60 \mathrm{~min}$ of reaction, phenol and cyclohexanone were the end products as shown in Fig. 3(a-c). With the increase in temperature the conversion of 2,4-DCP improved, similar results were reported by Calvo et al. (2004).

The influence of temperature on the rate constant of a reaction is represented by the original equation of Arrhenius $\mathrm{k}=\mathrm{A}_{\exp }\left(\frac{E_{a}}{R T}\right)$. The parameter of this relation activation energy $\left(E_{\mathrm{a}}\right)$ and pre exponent frequency factor $(\mathrm{A})$ will be calculated using the linear regression analysis and applying the results presented in Fig. 4 (graph of 1/T along X-axis and $\ln -\mathrm{k}$ along Y-axis) and the calculated activation energy is $43 \mathrm{KJ} / \mathrm{mol}$ indicating that the reaction occurred under surface reaction rate controlled conditions with negligible resistance to mass transfer as described by Satterfield (1970) and it is in accordance with the energy of activation for 2,4-DCP over Pd/C calculated by Yuan and Keane (2003).

Effect of catalyst loading. The change/variation in catalyst loading was carried out to investigate the optimum value for the treatment of 2,4-DCP. The experiments were carried out at different amounts of catalyst loading under the reaction conditions i.e., initial concentration of 2,4-DCP was $489 \mathrm{mg} / \mathrm{L}, 5 \% \mathrm{Pd} / \mathrm{C}$, $25^{\circ} \mathrm{C}$ and at 1 bar. As per result (Fig. 5), the increase in catalyst loading results in increased removal of 2,4-DCP. The top sketch of Fig. 6(a-c) depicts that 2$\mathrm{CP}$ and 4-CP were intermediate products but the ultimate conversion was predominantly phenol with minor 

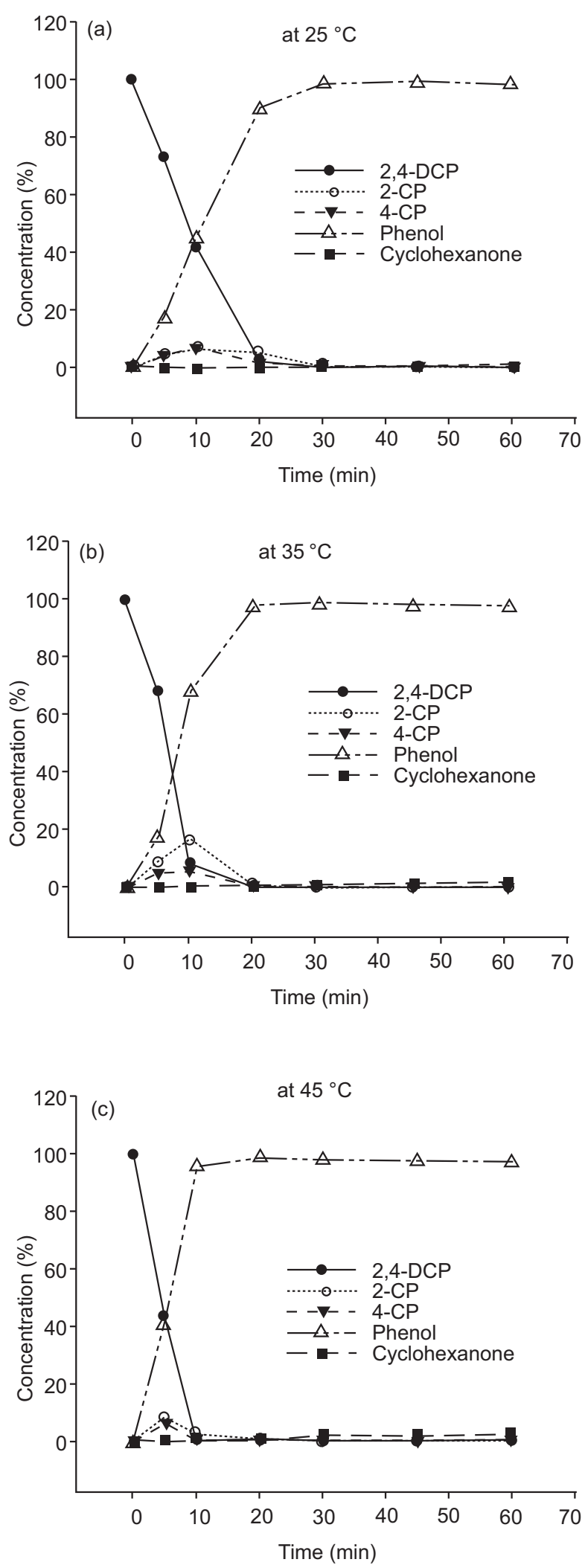

Fig. 3(a-c). The effect of temperature on the hydro-dechlorination of 2,4-DCP (a) at $25^{\circ} \mathrm{C}$, (b) $35^{\circ} \mathrm{C}$ and (c) at $45^{\circ} \mathrm{C}$. amount of cyclohexanone. As reported by Yuan and Keane (2003) the cyclohexanone was formed over Pd/C catalyst on the completion of hydrodechlorination after phenol with the 2-CP as the only intermediate product. However, in the present study, both 2-CP and 4-CP were formed as the intermediate products but end products were only phenol and cyclohexanone.

Effect of initial concentration. The influence of initial concentration of 2, 4-DCP on hydrodechlorination was studied with $5 \% \mathrm{Pd} / \mathrm{C}$ catalyst loading at $25^{\circ} \mathrm{C}$ under atmospheric pressure and at dispersion height of $40 \mathrm{~cm}$. Figure $6(\mathrm{a}-\mathrm{c})$ shows the effect of initial concentration on the catalytic hydrodechlorination of 2,4-DCP. With the increase in the initial concentration of 2, 4-DCP the time required for CHDC reaction was

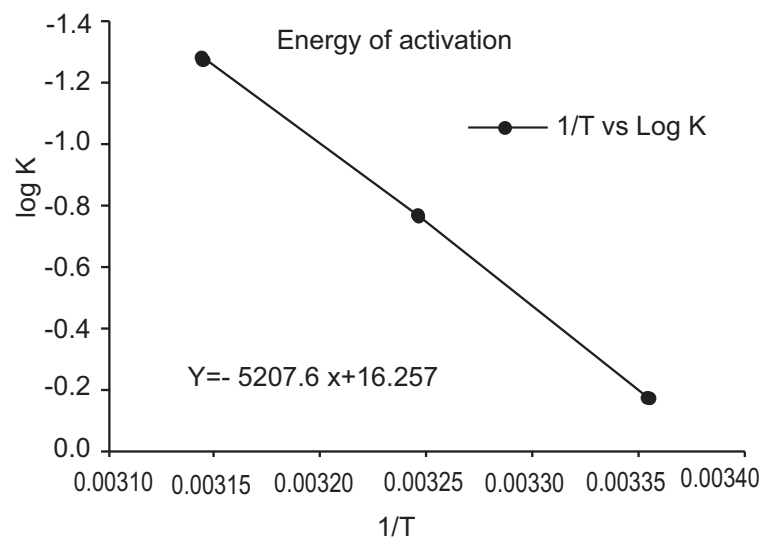

Fig. 4. Arrhenius plot of the rate constant measured in the range $298-318 \mathrm{~K}$.

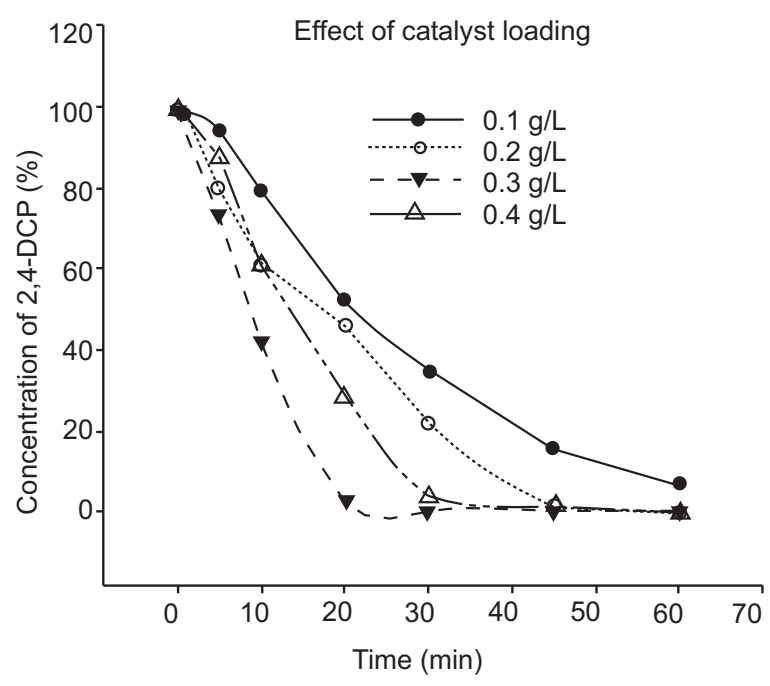

Fig. 5. The effect of catalyst loading on CHDC of 2,4-DCP at $25^{\circ} \mathrm{C}$. 


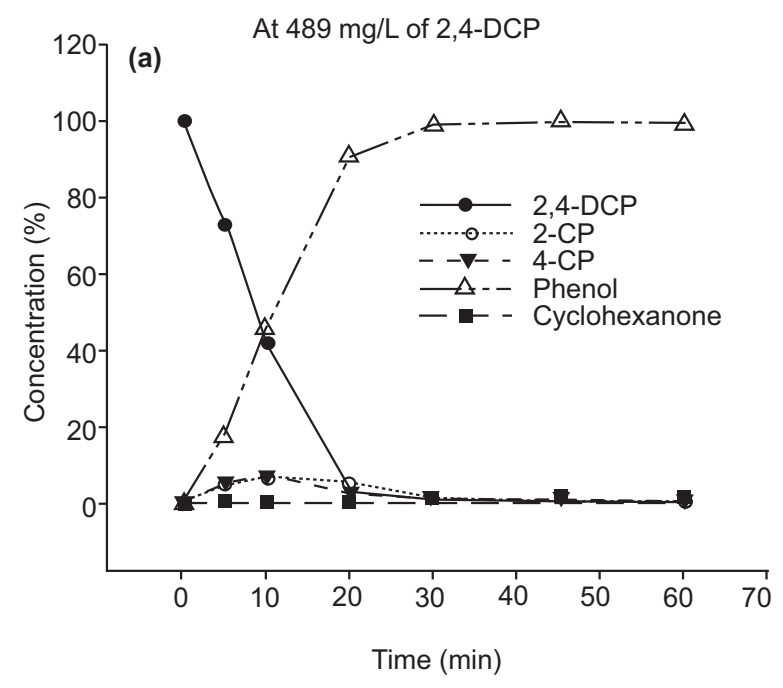

At $978 \mathrm{mg} / \mathrm{L}$ of 2,4-DCP
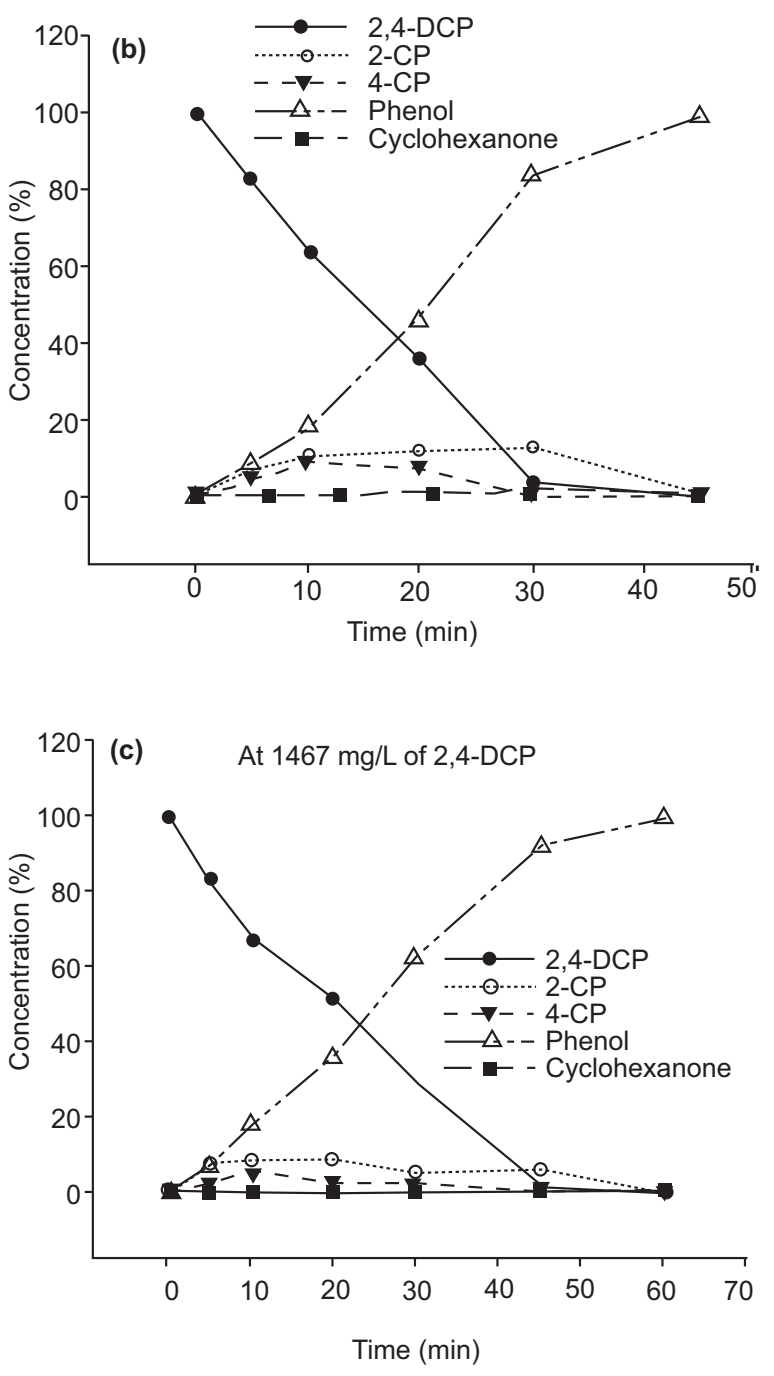

Fig. 6(a-c). The effect of initial concentration on the CHDC of 2,4-DCP. also increased. More cyclohexanone was produced when $978 \mathrm{mg} / \mathrm{L}$ of 2, 4-DCP was used and in case of $1467 \mathrm{mg} / \mathrm{L}$ of 2,4-DCP, more phenol was produced in the end products.

\section{Conclusion}

The goal of this research was to develop optimum reaction parameters for the CHDC of 2, 4-DCP and suitability of $\mathrm{CDCR}$ as an efficient reactor technology. It was shown that 2, 4-DCP was almost completely hydrodechlorinated predominantly to phenol and fractions of this phenol was further hydrogenated to cyclohexanone at $25^{\circ} \mathrm{C}$ under 1 atmospheric pressure in water with $5 \% \mathrm{Pd} / \mathrm{C}$ catalyst loading with respect to reactant. The results indicate that the application of CDCR reactor in the CHDC is the promising and efficient technique for pollution abatement. The inherent characteristics of CDCR facilitates the reaction and in batch reactors offers less time to degrade the 2, 4DCP. The calculated activation energy is $43 \mathrm{KJ} / \mathrm{mol}$ which indicates surface reaction rate controlled exhibiting efficient mass transfer in CDCR.

\section{Acknowledgement}

This study was supported by the Higher Education Commission of Pakistan vide NRPU P-1811/RND/119245 and University of the Punjab, Lahore, Pakistan.

\section{References}

Berg, L.G., Glas, B., Swanson, S.E., Rappe, C., Paul, K.G. 1990. Peroxidase-catalyzed oxidation of chlorophenols to polychlorinated dibenzo-p-dioxins and dibenzofurans. Archive of Environmental Contamination and Toxicology, 19: 930-938.

Czaplicka, M. 2004. Sources and transformations of chlorophenols in the natural environment. Science of the Total Environment, 322: 21-39.

Czaplicka, M. 2001. Determination of phenols and chlorophenols in bottom sediments. Chromatographia, 53: 470-473.

Concibido, N.C., Okuda, T., Nakano, Y., Nishijima, W., Okada, M. 2005. Enhancement of the catalytic hydrodechlorination of tetrachloroethylene in methanol at mild conditions by water addition. Tetrahedron Letters, 46: 3613-3617.

Calvo, L., Mohedano, A.F., Casas, J.A., Gilarranz, M.A., Rodrýguez, J.J. 2004. Treatment of chlorophenols bearing wastewaters through hydrodechlori- 
nation using $\mathrm{Pd} /$ activated carbon catalysts. Carbon, 42: 1377-1381.

Da-Silva, J.W., Bruns, R.E., Cobo, A.J.G. 2007. Study of the reaction conditions for the hydrodechlorination of pentachlorophenol on palladium catalysts. Chemical Engineering Journal, 131: 59-64.

Dursun, G., Ozer, A., Elibol, M., Ozer, D.1999. Mass transfer characteristics of a fermentation broth in a reactor: co-current downflow contacting reactor. Process Biochemistry, 34: 133-137.

Diaz, E., Casas, A., Mohedano, A.F., Calvo, L., Gilarranz M.A., Rodriguez, J.J. 2008. Kinetics of the hydrodechlorination of 4-chlorophenol in water using $\mathrm{Pd}$, $\mathrm{Pt}$, and $\mathrm{Rh} / \mathrm{Al}_{2} \mathrm{O}_{3}$ catalysts. Industrial \& Engineering Chemistry Research, 47: 3840-3846.

EPA, 2005. Proposition 65, Office of Environmental Health Hazard, EPA, California, USA.

Gomez-Sainero, M.L., Seoane, X.L., Tijero, E., Arcoya, A. 2002. Hydrodechlorination of carbon tetrachloride to chloroform in the liquid phase with $\mathrm{Pd} /$ carbon catalyst. Study of mass transfer steps. Chemical Engineering Science, 57: 3565-3574.

Gomez-Sainero, M.L., Seoane, X.L., Tijero, E., Arcoya, A., Cirtis, A. 2000. Hydrodechlorination of carbon tetrachloride to chloroform in the liquid phase with metal supported catalysts. Effect of catalyst components. Industrial and Engineering Chemistry Research, 39: 2849-2854.

Graham, L.J., Atwater, J.E., Jovanovic, G.N. 2005. Chlorophenol Dehalogenation in a Magnetically. Stabilized Fluidized Bed Reactor. AIChE Journal, 52: 1083-1093.

Gryglewicz, G., Stolarski, M., Gryglewicz, S., Klijanienko, A., Piechocki, W., Hoste, S., Driessche, V.I., Carleer, R., Yperman, J. 2006. Hydrodechlorination of dichloro-biphenyls over $\mathrm{Ni}-\mathrm{Mo} / \mathrm{Al}_{2} \mathrm{O}_{3}$ catalysts prepared by spray-drying method. Chemosphere, 62: 135-141.

Jujjuri S., Keane, M.A. 2009. Catalytic hydrodechlorination at low hydrogen partial pressures: Activity and selectivity response. Chemical Engineering Journal, 157: 121-130.

Knuutinen, J., Palm, H., Hakala, H., Haimi, J., Huhta, V., Salminen, J.1990. Polychlorinated phenols and their metabolities in soil and earthworms of sawmill environment. Chemosphere, 20: 609-623.
Keane, M.A., Murzin, D.Y. 2001. A kinetic treatment of the gas phase hydrodechlorination of chlorobenzene over nickel/silica: beyond conventional kinetics. Chemical Engineering Science, 56: 3185 3195.

Lu, X.X., Boyes, A.P., Winterbottom, J.M.1996. Study of mass transfer characteristics of co-current downflow bubble column reactor using hydrogenation of iatonic acid. Chemical Engineering Science, 51: 2715-2720.

Meshesha, B.T., Chimentao, R.J., Medina F., Sueiras, J.E., Cesteros, Y., Salagre, P., Figueras, F. 2009. Catalytic hydrodechlorination of 1,2,4-trichlorobenzene over $\mathrm{Pd} / \mathrm{Mg}(\mathrm{Al}) \mathrm{O}$ catalysts. Applied Catalysis B: Environmental, 87: 70-77.

Murena, F., Gioia, F. 2004. Diffusional kinetics in the catalytic hydrodechlorination of chlorobenzene in multiphase aqueous mixtures. Applied Catalysis A: General, 271: 145-151.

Mori, T., Kubo, J., Morikawa, Y. 2004. Hydrodechlorination of 1,1,1-trichloroethane over silica supported palladium catalyst. Applied Catalysis A: General, 271: 69-76.

Nishijima, W., Ochi, Y., Tsung-Yuech, T., Nakano, Y., Okada, M.2004. Catalytic hydrodechlorination of chlorinated ethylenes in organic solvents at room temperature and atmospheric pressure. Applied Catalysis B: Environmental, 51: 135-140.

Ochuma, I. J., Fishwick, R. P. 2007a. Photocatalytic oxidation of 2,4,6-trichlorophenol in water using a cocurrent downflow contactor reactor (CDCR). Journal of Hazardous Materials, 144: 627-633.

Ochuma, I.J., Osibo, O.O. 2007b. Three-phase photocatalysis using suspended titania and titania supported on a reticulated foam monolith for water purification. Catalysis Today, 128: 100-110.

Satterfield, C.N. 1970. Mass Transfer in Heterogeneous Catalysis, Chapter No.1. pp. 3-5, MIT Press, USA.

Sithole, B.B., Williams, D.T.1986. Halogenated phenols in water at forty Canadian potable water treatment facilities. Journal of Association of Official Analytical Communities, 69: 807-810.

Vaidya, P.D., Mahajani, V.V. 2004. Studies in hydrotreatment as a unit process to destroy 4-chlorophenol in aqueous stream over $\mathrm{Ru}-\mathrm{Pd} / \mathrm{TiO}_{2}$ catalyst. Applied Catalysis B: 
Environmental, 51: 21-31.

WHO, 1996. Guideline for Drinking-Water Quality, vol. 2, $2^{\text {nd }}$ edition, World Health Organization, Geneva, Switzerland.

Winterbottom, J.M., Marwan, H., Stitt, E.H., Natividad, R. 2003. The palladium catalysed hydrogenation of 2-butyne-1,4-diol in a monolith bubble column reactor. Catalysis Today,79-80: 391-399.
Xia, C., Liu, Y., Zhou, S., Yang, C., Liu, S., Guo, S., Liu, Q., Yu, J., Chen, J. 2009. The influence of ion effects on the Pd-catalyzed hydrodechlorination of 4-chlorophenol in aqueous solutions. Catalysis Communications, 10: 1443-1445.

Yuan, G., Keane, M.A. 2003. Liquid phase catalytic hydrodechlorination of chlorophenols at $273 \mathrm{~K}$. Catalysis Communications, 4: 195-201. 